\title{
NOTAS
}

\section{Huidobro y el Creacionismo}

(A propósito del libro Huidobro o la vocación poética de David Bary ${ }^{1}$ )

$\mathbf{L}$ As letras americanas de los años 10 y 20 conocen un renuevo de interés. Sin duda entre su circunstancia y la nuestra hoy deben de haber ciertas analogías, más bien sentidas que conscientes. El seminario de Juan Larrea en La Plata y las dos tesis que se preparan an la Sorbona sobre Huidobro ${ }^{2}$ versan en gran parte sobre un problema siempre actual: la lógica propia del lenguaje como diferente de la lógica del pensamiento (logos versus ratio). Por otra parte, nos seguimos debatiendo desde aquellos años por saber de qué modo y hasta qué punto se pueden integrar las letras en una teoría general de la estética, y por consiguiente, cuáles son y deben ser sus relaciones con las demás artes.

Rico en signficación es el semi-fracaso de la temeraria empresa de Huidobro. Conviene meditarlo. El profesor Bary se propone en este libro definir y valorar la obra del poeta en cada una de sus etapas y mostrarnos a través de las vacilaciones y las contradicciones del vate en busca de inspiración, los poderosos y magníficos que pueden ser tantos callejones sin salida. Su estudio está basado en los textos poéticos publicados y los sin publicar, pero también en los recuerdos personales, recogidos por el investigador, de los campañeros de "farra" en París del poeta chileno.

1 Colección filológica XXI, Universidad de Granada, Granada, 1963, 137 págs. C.S.I.C. Este libro es como síntesis de artículos publicados ya por Bary en I. Revista iberoamericana, la Revista hispánica moderna y Cuadernos americanos.

2 De la señora Pizarro de Mora, chilena; y del señor Yurkievich, argentino. 
Pues bien, la "farra" original se convirtió tápidamente en numerosas capillas, cada una con sus santos y un papa que cuidaba de la ortodoxia del grupo: futurismo, dadaísmo, creacionismo, ultraísmo, hasta el mismo surrealismo.

¿Quién fue Huidobro? Bary no oculta la triste verdad: un mitómano afligido a la vez por la manía de la grandeza (y se arrogaba la primacía en todos los descubrimientos poéticos de esas escuelas). Aspiraba Huidobro a ser "el primer poeta de América", luego "el primer poeta de su lengua", luego "el primer poeta de su siglo", en breve "un pequeño Dios" en la religión desde luego monoteística de las letras. Para convencer a todos, Huidobro no vacilaba en falsificar datos y especialmente fechas, atribuyéndose generosamente el mérito de todos los hallazgos. Este es un punto importante del método seguido por Bary en sus investigaciones ya que tuvo que establecer la verdadera cronología de poemas y textos en prosa, alterada por el vanidoso poeta. Luego, sobre esas bases firmes, Bary procede a fundar su estudio de la evolución rápida de la inspiración de Huidobro, desde el cromo post-romántico y el modernismo deslédo hasta los primeros albores de la imagen creacionista. Describe con gran certeza las reglas y convenciones flotantes del juego poético, las variaciones en la visión del objeto y la tensión creciente entre la emotividad y la fría disciplina a la que quería someter la forma en sí.

Después de plantar esos jalones, David Bary puede abordar la cuestión "palpitante": ¿Qué es el creacionismo? Primero lo define diferenciándolo de la interpretación romántica, enteramente subjetiva del mundo exterior; del experimento poético al modo de Baudelaire; de la exploración sistemática de un universo hasta ahora desconocido a la manera de Rimbaud. A esos diferentes métodos de acercarse a la realidad, Huidobro y sus compañeros sustituyen la invención de objetos nuevos en forma de poemas sin conexiones entre sí, ya que no constituyen un universo poético coherente: "incoherentes en sí mismos y formados con elementos suministrados por la sensibilidad y los que luego hacen perder su sentido funcional". ${ }^{3}$ La doctrina poética de Huidobro pierde su valor de atracción sobre los poetas de su generación a partir del momento en que Apollinaire, aceptando esas premisas, integra los objetos casi creados en un mundo como super-real, una realidad latente en cada uno de nosotros que el

3 Por ejemplo, "centauto" o "fauno" o bien la fábula de Prometeo, o la imagen de Medusa con las serpientes enroscadas en su cabellera. Compárese: "Al horitaño del montazonte, la violondrina y el goloncelo"; y otras formas de hibridación; y compárese la ficción de Altazor esencialmente ambigüa. 
poeta va a revelar, como inocente que es y usando el poder de medium que le dio la Naturaleza. Pues bien, Huidobro, por mantener su pose de inventor genial, se ve forzado a llevar a sus últimas consecuencias su poética, a pesar de que todos sus sentimientos panteístas más profundos expresados desde su juventud le llevaban a abandonar esa visión caótica del univero poético y a adoptar la visión integrada de Apollinaire.

El creacionismo empieza con la publicación de la revista Nord-Sud (1917). Ahí da Huidobro doce poemas. Es difícil delimitar la aportación propia de Reverdy y la de Huidobro. Muchas veces los antecedentes de uno y otro más bien nos harían hablar de una coincidencia o de un encuentro, términos más justos que los de influencia o de originalidad singular. Pero lo que resalta ya en esa revista es la prodigiosa invención verbal del chileno y su capacidad deslumbrante para crear imágenes vivas a partir de elementos dislocados de nuestro campo visual. A pesar de ello, la fuerza vital de la poesía de Apollinaire y la inteligencia de Cendrars ya ganan la partida. Huidobro, por no quedar rezagado, se vuelve también hacia el porvenir y se hace poeta mago, profeta, y se pronuncia contra la literatura en cuanto tal (anti-literatura): ejs. "Automne regulier", "Tout a coup" (1925) y "Salle 14" (inédito). En Altazor (1931) estalla al fin la contradicción. ¡Cómo puede ese hombre de letras típico cultivar la antiliteratura! ¡Cómo va a sacrificar su yo tan mimado en aras de una superrealidad que se sirve del poeta como de un mero instrumento para revelarse! Otra vez rezagado Huidobro intenta superar el surrealismo de Breton: inventa un "cristianismo ateo". Pero Altazor no es sino la parodia de una experiencia mística totalmente ficticia. Es el fracaso. Las bases freudianas y marxistas de Breton correspondían a un momento de nuestra coyuntura cultural. Pero aquel misticismo de Huidobro quedaba en el aire. Entonces, para no dejarse ir de la mano, Huidobro se proclama comunista: convierte en adhesión provocativa los anhelos caprichosos de rebeldía que de vez en cuando manifestara en su "carrera" de poeta millonario. $\mathrm{Y}$ da en escribir novelas pesadas en las que exalta al proletariado y satiriza a la burguesía. Con razón Bary subraya el carácter hispánico de ese anarquismo de las "clases pasivas", que no tiene nada que ver ni con Marx ni con Bakunin. Por cierto con esa mala literatura no recobra el puesto de líder en el pelotón de variguardia de las letras ni francesas ni españolas. Al fin llega la hora de la verdad. Antes de morir, Huidobro, en una carta, confiesa su fracaso a Juan Larrea. Pero Narciso aquí se convierte en Erostrato; el vanidoso poeta se propone incendiar el templo que no le 
admitió como Gran Sacerdote: "Nosotros somos los últimos representantes irresignados de un sublime cadáver". Efectivamente la poética de Huidobro quedará como una tentativa desesperada por prolongar la vida moribunda de la "Literatura", esa emanación nauseabunda del ghetto de los hombres de letras.

Mientras tanto, otro poeta chileno, Pablo Neruda, se preparaba para dar a esa literatura de conventillos bizantinos el golpe de muerte. El poeta épico de los inmensos frescos, con un poderoso manotazo quitaba del escenario al poeta "de caballete", autor de pequeños poemas exactos. Paralelamente y mutatis mukandis Picasso, genial destructor de la Pintura, eclipsaba a Juan Gris, el perfecto poeta del cubismo.

Pero en la comunidad demasiado cultural de la lengua española, Huidobro había encontrado cierta resonancia. Había demostrado que la imagen no sólo podía servir para dar una segunda dimensión poética al objeto real, para "ilustrarlo", sino que podía crear por sí sola un objeto nuevo, original, desconocido de nuestra visión fisiológica, aprehensible tan sólo por un sexto sentido: la facultad nuestra de hacer coincidir no solamente el universo mental con el de los objetos sino también con el mundo. En España, razón, sensibilidad y afectividad imperaban desde siempre en la poesía con un equilibrio distinto en el seno de aquel triunvirato, según las épocas. A partir de Huidobro, el logos propio del lenguaje consigue derrocar esa dictadura. Las palabras no sólo son signos de ideas, sensaciones y afectos sino que tienen su vida autónoma y se organizan según sus propias leyes, sin el poeta y hasta contra él.

Nos hemos limitado aquí a esbozar la génesis del objeto creado, poema, según Huidobro. Nuestro análisis no da cuenta de la riqueza del estudio de Bary, de su excelente información histórica, y de las certeras valoraciones estéticas que le dan su aura y su trasfondo. Sin duda, como lo dice el mismo autor, queda mucho por hacer. Permítasenos hacer algunas indicaciones, en parte utilizadas por los dos futuros doctores míos de la Sorbona: una encuesta minuciosa sobre las actividades literatias de Huidobro en París, la definición de cada una de las numerosas capillas literarias de su tiempo y la formulación de sus artes poéticas. Sobre todo, habría que estudiar la lógica interna a la que obedece el poema como objeto-creado, desde su proyecto hasta su realización, o digámoslo así, formular el orden oculto de esa función de fuegos artificiales tan brillantes como aparentemente sin ligazón.

Pero el camino está trazado. En el estado actual de nuestro conocimiento el trabajo de Bary es imprescindible para el que quiera explorar 
ese jardín franco-español de flores nunca vistas ni olidas que el poeta supo cultivar en medio de la selva española"."

Université de Paris, Charles Aubrun

4 Es de sentir que los poemas franceses citados aparezcan plagados de ertores de imprenta. Para la comodidad del lector hubiera sido útil un índice onomástico. 
